\title{
A study of interaction of cigarette smoke with alpha- 1 antitrypsin and adenosine deaminase in patients of chronic obstructive pulmonary diseases (COPD) and antioxidant role of vitamin $\mathrm{E}$
}

\author{
Anita M. Raut ${ }^{1}$, Dhananjay V Andure ${ }^{2, *}$, Ramchandra K. Padalkar ${ }^{3}$, Sangita M. Patil ${ }^{4}$, Sonali S. Bhagat ${ }^{5}$ \\ 1,4,5 Assistant Professor, ${ }^{2}$ Associate Professor, ${ }^{3}$ Professor and Head, Dept. of Biochemistry, Dr. VVPF's Medical College \& \\ Hospital, Ahmednagar, Maharashtra, India
}

*Corresponding Author: Dhananjay V Andure

Email: drdhananjayandure@gmail.com

Received: $2^{\text {nd }}$ August, 2018

Accepted: $9^{\text {th }}$ August, 2018

\begin{abstract}
Lungs are the only organs which are continuously exposed to external environment through the process of breathing. The cigarette smoking is main leading cause of various morbidities related to lungs. Adenosine deaminase (ADA) and alpha-1 antitrypsin (A1AT) are the two very important parameters of which ADA is required for maintaining proper immunity and A1AT is required for resolving oxidant stress on lungs by various mechanism. In the present study we evaluated the level of these parameters in active cigarette smokers without lung disease and COPD patients, and found that ADA level was significantly high in healthy smokers and COPD patients as compared to healthy controls $(\mathrm{P}<0.001)$. Whereas significantly lower levels of alfa-1 antitrypsin $(\mathrm{P}<0.001)$ as compared to healthy controls. The present study consist of total 100 subjects as healthy controls, 60 as active smokers and 60 as COPD patients. We also assessed effect of vitamin E supplementation in smokers and COPD patients. It has been found that there is significant recovery in the above mentioned parameters after treatment with vitamin E; confirming protective antioxidant role of vitamin $\mathrm{E}$. Thus the present study confirmed the deliberate overactivity of adenosine deaminase and decreased activity of alpha- 1 antitrypsin in COPD patients and smokers leading to oxidative stress and various lung diseases.
\end{abstract}

Keywords: Adenosine deaminase, Alpha-1 antitrypsin, Chronic obstructive pulmonary diseases (COPD), Vitamin E and Cigarette smoke (CS).

\section{Introduction}

The cigarette smoke contains thousands of toxic chemicals including 43 cancer causing carcinogens and more than 400 toxins these includes nicotine, tar, carbon monoxide, acetone, vinyl chloride, 1Nitrosodimethylamine, hydrogen cyanide, arsenic, nitric oxide and many others. Toxins in tobacco smoke harm the body once they enter through the nose or mouth. They damage tissue and cells all the way to the from mouth to lungs. When smoke is inhaled, toxic chemicals are absorbed in the lungs. As a result, smoking causes various lung diseases, including chronic obstructive pulmonary disease (COPD) in chronic smokers; and increases the risk for respiratory infections. ${ }^{1,2}$ Smoking is a widespread behavior among adolescents and a major subject of discussion all around the globe. In various studies, It is been reported that more than $15 \%$ of all smokers and about $26 \%$ of heavy smokers leads to Chronic Obstructive Pulmonary Disease (COPD), typically characterized by persistent airflow obstruction and chronic inflammation of the airways. Thus COPD symptomatically can lead to small airway disease (obstructive bronchiolitis) or parenchymal destruction (emphysema) depending upon level of destruction. ${ }^{3-6}$

Adenosine deaminase one of the crucial enzyme is also known as adenosine aminohydrolase which is involved in purine metabolism. It has significant role in proper maintenance of immune system. ${ }^{7}$ It has got two forms of isoenzymes ADA1 \& ADA2 which are located on different genes. ${ }^{8}$ In humans ADA1 is $\mathrm{Zn}$ binding protein and its activity is in lymphocytes and macrophages. But the other is o form type i.e. ADA2; very little is known about this form of $\mathrm{ADA}$ and it might be having role in monocytes. ${ }^{9,10}$

At present only few studies are reported regarding ADA activity among smokers and smoking induced diseases. ${ }^{11}$

Alpha-1 antitrypsin (A1AT) is a protein belonged to the serpin superfamily. It is located in SERPINA 1 gene in humans. It is protease inhibitor, also known as alpha-1 proteinase inhibitor; as it inhibits proteases not just trypsin.

It is found that posttranslational modifications of alpha-1 antitrypsin in patients with chronic obstructive pulmonary disease, is that of oxidation, might be because of exposure to cigarette smoke toxins. Reactive oxygen and nitrogen species, which are increased in smokers, may target and modify the alpha-1 antitrypsin. ${ }^{12}$ Alpha-1 antitrypsin deficiency is inherited disorder, characterized by low serum level of alpha- 1 antitrypsin below the reference range of 90-200 mg/dl. A1AT neutralizes the activity of neutrophil elastase, a protease that destroys elastin and other connective tissue components in the lung; however, a deficiency of alpha-1antitrypsin represents an imbalance in elastase and increases the risk of emphysema because of lung destruction. ${ }^{13,14}$ 
In the present study, we assessed the levels of ADA and A1AT in the healthy smokers and well established COPD patients; compared with healthy controls. We also evaluated the effect of vitamin E supplementation in counteracting cigarette smoke toxins in vivo in above groups.

\section{Aims and Objectives}

The present work was planned to study interaction of cigarette smoke with following parameters were given as below:

1. To known the presences of possible damage by cigarette smoke by analysing level of alfa-1 antitrypsin.

2. To evaluate alteration due to cigarette smoke by estimating concentration of adenosine deaminase.

3. To analyse the non enzymatic antioxidant vitamin $\mathrm{E}$ in smokers and patients with COPD.

\section{Material and Method}

The present study was conducted in the Department of Biochemistry, Dr. Vithalrao Vikhe Patil foundation's Medical College and Hospital Ahmednagar. Total duration of study is 3 years. It is a original study type. The patients selected for the present study were attending indoor/outdoor patient department from Dr. Vithalrao Vikhe Patil Memorial Hospital, Ahmednagar.

Exclusion Criteria: Smokers with Hypertension, Malignancy, Cardiac failure, recent surgery, severe endocrine, hepatic, renal diseases or lung disorders were excluded.

Inclusion Criteria: In our study, we divided subjects in three groups as follows:

Healthy Smokers Subjects: All smokers were active smokers without any lung disease. 60 healthy smokers with smoking history of more than 10-20 cigarettes per day for more than last two years, in the age group of 20-60 years were included. Their thorough examination was done at our hospital by chest \& TB physicians, they undergone complete physical examination and required investigations viz spirometry etc. The healthy smokers were shown all tests within normal limit and were completely symptoms free.

Established COPD Subjects: As well as 60 well established, smoking induced COPD patients were included in the study. They were having smoking habit of 10-20 cigarettes per day for more than last two years and showed COPD on examination. They were diagnosed by our hospital Chest \&TB physicians after their complete physical examination and investigation including spirometry. Patients in the clinically stable phase of disease with FEV1/FVC $<70 \%$ and having COPD more than 2 years were included. Active underlying cause of COPD patients were active smoking, environmental pollution, atopy, tuberculosis.
The Healthy Control Subjects: Above two groups were compared with 100 healthy control subjects. The control subjects were completely healthy, nonsmokers and showed no abnormality on clinical examinations and were completely symptom less. Informed consent was obtained from each participant in the present study. The study was cleared by institutional ethics committee.

$5 \mathrm{ml}$ blood was collected from each subject in the plain bulb and serum were collected from respective bulbs by centrifugation at $3000 \mathrm{rpm}$ for 10 minutes at room temperature. All samples were analysed on the same day of collection.

The activity of serum alpha-1 antitrypsin (A1AT) was assayed by immune diffusion method of Macini using Kits of Bioscientofica Co. Argentina; ${ }^{15}$ and serum adenosine deaminase (ADA) activity was assayed by Giusti G. L. method. ${ }^{16}$ The serum vitamin E $(\alpha-$ Tocopherol) was estimated by the method of Baker and Frank. ${ }^{17}$ Initial base line investigation were carried out. The healthy smoker and established COPD subject groups were given supplementation of vitamin E (Cap Evion-E Merck) $400 \mathrm{mg}$ twice daily for 8 weeks. After this supplementation healthy smokers and COPD group subject's were checked for alpha-1 antitrypsin level and adenosine deaminase activity and compared with each other, base line results and controls statistically.

Statistical analysis was carried out using student unpaired ' $t$ ' test. Probability values $<0.05$ was considered as significant. Also data were expressed in mean \pm SD form.

\section{Results}

In this study, we studied different parameters to understand interaction of cigarette smoke with serum levels of adenosine deaminase, alfa- 1 antitrypsin and vitamin E. In this study we found that vitamin E, which is crucial antioxidant vitamin was found to be significantly decreased in healthy smokers and COPD patients $(\mathrm{P}<0.001)$ (Fig. 1). At the same time adenosine deaminase level was significantly higher in healthy smokers and COPD patients $(\mathrm{P}<0.001)$. Alfa-1 antitrypsin levels signficantly decreased in both healthy smokers and COPD patients $(\mathrm{P}<0.001)$ (Fig. 2). We also studied the effect of vitamin $\mathrm{E}$ supplementation in above said groups and found that there was significant recovery in levels of serum adenosine deaminase and alfa-1 antitrypsin levels in healthy controls and COPD patients (Table 1). 
Table 1: The levels of serum adenosine deaminase and alpha-1 Antitrypsin in defferent groups before and after regular supplementation of vitamin $E$

\begin{tabular}{|l|c|c|c|c|c|c|}
\hline S. No. & Parameter & \multirow{2}{*}{$\begin{array}{c}\text { Healthy } \\
\text { control }\end{array}$} & \multicolumn{2}{|c|}{ Smokers } & \multicolumn{2}{c|}{ COPD } \\
\cline { 4 - 7 } & & $\begin{array}{c}\text { Before Vit. E } \\
\text { Suppli. }\end{array}$ & $\begin{array}{c}\text { After Vit. E } \\
\text { Suppli. }\end{array}$ & $\begin{array}{c}\text { Before Vit. E } \\
\text { Suppli. }\end{array}$ & $\begin{array}{c}\text { After Vit. E } \\
\text { Suppli. }\end{array}$ \\
\hline 1. & $\begin{array}{c}\text { Vitamin E } \\
(\mathrm{mg} / \mathrm{dl})\end{array}$ & $0.927 \pm 0.12$ & $0.31 \pm 0.09^{*}$ & $0.88 \pm 0.06^{*}$ & $0.36 \pm 0.05^{*}$ & $0.91 \pm 0.07^{*}$ \\
\hline 2. & $\begin{array}{c}\text { Adenosine } \\
\text { Deaminase } \\
\text { (IU/L) }\end{array}$ & $16.01 \pm 1.61$ & $25.78 \pm 0.78^{*}$ & $16.66 \pm 0.71^{*}$ & $28.01 \pm 3.81^{*}$ & $19.2 \pm 0.70^{*}$ \\
\hline 3. & $\begin{array}{c}\text { Alfa-1 } \\
\text { Antitrypsin } \\
\text { (mg/dl) }\end{array}$ & $146 \pm 23.12$ & $132.26 \pm 18.78^{*}$ & $140.6 \pm 13.45^{*}$ & $106.4 \pm 9.1^{*}$ & $121.26 \pm 2.18^{*}$ \\
\hline
\end{tabular}

All values are expressed as Mean \pm SD. $(* \mathrm{P}<0.001)$

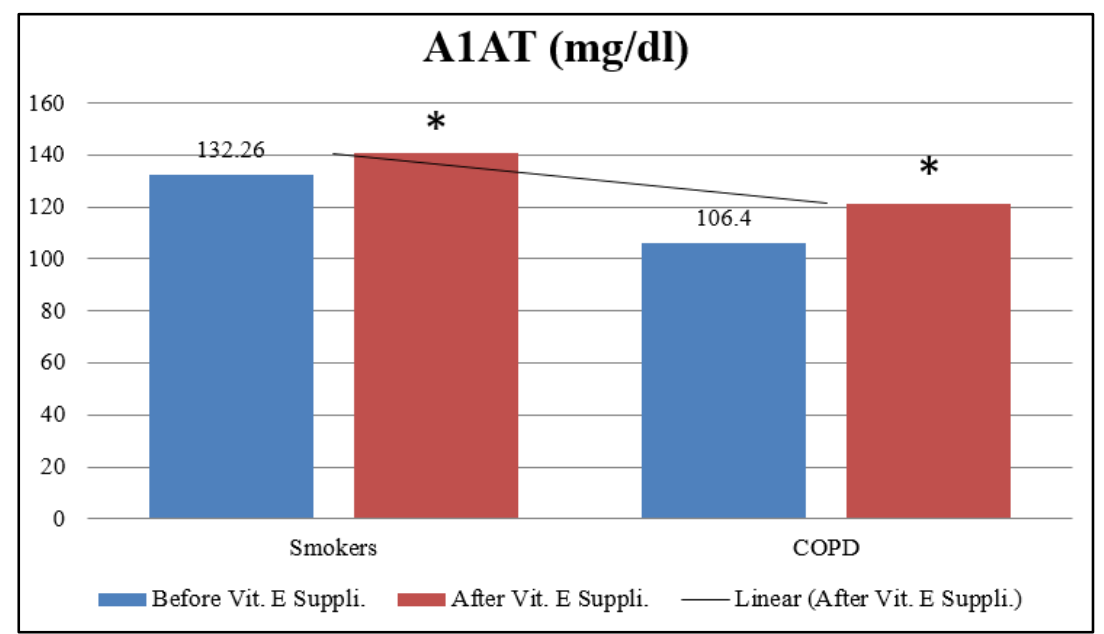

Fig. 1: The level of Alpha-1 Antitrypsin (A1AT) (mg/dl) in healthy smokers and COPD subjects $(* \mathrm{P}<0.001$ as compared to healthy controls.)

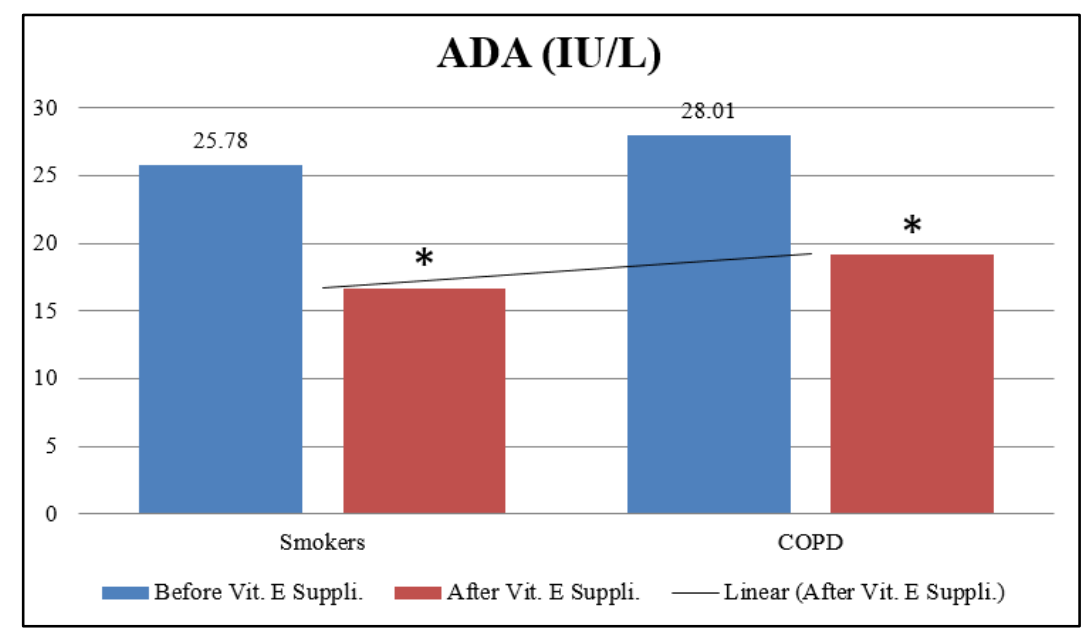

Fig. 2: The level of Adenosine Deaminase (ADA) (IU/L) in healthy smokers and COPD subjects $* \mathrm{P}<0.001$ as compared to healthy controls.

\section{Discussion}

The cigarette smoking is the leading and yet preventable cause of Chronic Obstructive Pulmonary Disease (COPD) due to chronic smoking habits. COPD is a major cause of chronic morbidity and mortality throughout the globe. The chronic airflow limitation is caused by a mixture of small airway obstructive bronchiolitis and parenchymal destruction in the form of emphysema. Globally, COPD is the 3rd leading 
cause of death and the 5th leading cause of loss of 'Disability Adjusted Life Years' (DALYs) as per projection of the Global Burden of Disease Study (GBDS). ${ }^{18}$

Alpha-1 antitrypsin is protein of serpina family. It has 394 amino acids in its structure and 3 carbohydrate side chains attached to asparagines. The amino acid methionine is present at position 358. It is susceptible to get converted to methionine sulfoxide by oxidants present in cigarette smoke, converting it to much less potent inhibitor of neutrophil elastase. ${ }^{19}$

Adenosine deaminase (ADA) also known as adenosine aminohydrolase plays crucial role in purine metabolism. It which catalyses the deamination of adenosine to inosine. It is been said to play the primary role in development and maintenance of immunity.

Different studies demonstrated change in ADA activities in pleural fluid of patients with COPD; which are more commonly associated with cigarette smoking habit. ${ }^{20}$ One more study also shows increased ADA activity in cigarette smokers compared to healthy nonsmokers which suggest its role in mediating some of the chronic health hazards of smoking like COPD, TB and other lung diseases; which were found to be associated with an increased levels of ADA and also reported positive correlation between pack size and ADA activity. ${ }^{21}$ In another study, it is found that in diabetic patients ADA was raised due to oxidant stress in diabetics, which was decreased after antioxidant therapy. ${ }^{22}$

Vitamin $\mathrm{E}$ is a lipid soluble chain breaking antioxidant vitamin that prevents lipid peroxidation. Although cigarette smoke is a potent source of oxidative stress that depletes vitamin $\mathrm{E}$ and other antioxidants in vitro it is not clearly known whether it has a similar effect in vivo particularly in human beings. One review study discussed the role of cigarette smoke on gamma- tocopherol nitration, its effect on alpha -tocopherol biokinetics in smokers, and the changes in the synthesis plasma concentrations and urinary excretion of the vitamin $\mathrm{E}$ metabolite in cigarette smokers. ${ }^{23}$

In one more study, it was found that the daily supplementation of $200 \mathrm{mg}$ of vitamin $\mathrm{E}$ for 8 weeks improved the oxidative stress state in cigarette smokers. ${ }^{24}$

\section{Conclusion}

Thus with the findings in the results, the present study concluded the release of adenosine deaminase from lung tissue suggesting lung parenchymal damage in cigarette smokers because of oxidant stress in smoke. There was also severe deficiency of alpha-1 Antitrypsin, and was the cause of lung parenchymal damage due to its antiprotein action. We also shown that regular supplementation of vitamin $\mathrm{E}$ can nullify the changes upto certain extent; so our study suggest the vitamin $\mathrm{E}$ role in boosting up the antioxidant property in the lung.

\section{Acknowledgement}

Authors acknowledge the immense help received from scholars whose articles are cited and included in references are also grateful to authors /editors publishers of all those articles, journals and books from where the literature for this article has been reviewed and discussed. Authors are also grateful to the management DVVPF'S Medical College Ahmednagar for their support and encouragement for carrying out this study.

\section{References}

1. Mortaz, E, Masjedi, M.R, Rahman I. Outcome of Smoking Cessation on Airway Remodeling and Pulmonary Inflammation in COPD Patients. Tanaffos. 2011;10:7-11.

2. Brunnemann, K.D., Hoffmann, D. Analytical studies on tobacco-specific N-nitrosamines in tobacco and tobacco smoke. Crit. Rev Toxicol. 1991;21:235-240.

3. Conti V, Corbi G, Manzo V, Pelaia G, Filippelli A, Vatrella A. Sirtuin 1 and aging theory for chronic obstructive pulmonary disease. Anal Cell Pathol. 2015.

4. Le Rouzic O, Pichavant M, Frealle E, Guillon A, SiTahar M, Gosset, P. Th17 cytokines: Novel potential therapeutic targets for COPD pathogenesis and exacerbations. Eur Respir J. 2017;50(4).

5. Li L, Zhang, M, Zhang L, Cheng Y, Tu X, Lu Z. Klotho Regulates Cigarette Smoke-Induced Autophagy: Implication in Pathogenesis of COPD. Lung. 2017;195:295-301.

6. Vij N, Chandramani-Shivalingappa P, Van Westphal C, Hole R, Bodas M. Cigarette smoke-induced autophagy impairment accelerates lung aging, COPD-emphysema exacerbations and pathogenesis. Am J Physiol Cell Physiol. 2018;314:C73-C87.

7. Pirincci N, Gecit I, Gunes M, Yuksel BM, Kaba M, Tanık S, et al. Serum adenosine deaminase, catalase and carbonic anhydrase activities in patients with bladder cancer. Clinics. 2012;67(12):1443-6.

8. Maier S, Galellis J, McDermid H. Phylogenetic Analysis Reveals a Novel Protein Family Closely Related to Adenosine Deaminase. J Mol Evol. 2005;61:776.

9. Pospisilova, H, Frebort I. Aminohydrolases acting on adenine, adenosine and their derivatives. Biomed Pap Med Fac Univ palacky Olomouc Czech Repub. 2007;151:3.

10. Mohammadtaheri Z, Mashayekhpour S, Mohammadi F, Mansoori D, Masjedi MR. Diagnostic Value of Adenosine Deaminase Isoenzyme (ADA2) and Total ADA in tuberculous pleural effusion. Tanaffos. 2005;4(15):37-42.

11. Devaranavadgi BB, Aski BS, Kashinath RT, Hundekari IA. Effect of Cigarette Smoking on Blood Lipids - A Study in Belgaum, Northern Karnataka, India. Global Journal of Medical Research. 2012;12(6).

12. Angelia D Lockett, Mary Van Demark, Yuan Gu, Kelly S Schweitzer, Ninotchka Sigua, Krzysztof Kamocki et al. Effect of Cigarette Smoke Exposure and Structural Modifications on the $\alpha-1$ Antitrypsin Interaction with Caspases. Molecular Medicine. 2012; 18:445-54. 
13. Pyng Lee, Thomas R. Gildea, James K. Stoller. Emphysema in nonsmokers: Alpha 1-antitrypsin deficiency and other causes. Cleveland clinic journal of Medicine. 2002;69(12):928-46

14. Dati F, Schumann G, Thomas L, et al. Consensus of a Group of Professional Societies and Diagnostic Companies on Guidelines for Interin Reference Ranges for 14 Proteins in Serum based on the Standardization against the IFCC/BCR/CAP Reference Material (CRM 470). Eur J Clin Chem Biochem. 1996;34:517-20.

15. Macini et al. The activity of alfa- 1 antitrypsin (A1AT) was assayed by immune diffusion method of Macini using Kits of Bioscientofica Co. Argentina.

16. Giuseppe Giusti. The quantitative determination of adenosine deaminase by method of Giuseppe Giusti and Bruno gallant. Bergmemer H. V. Ed Methods of enzymatic analysis N.Y. Academic Press Inc. 197:308323.

17. The Tiet estimation of Serum vitamin 'E' ( $\alpha$ - Tocopherol) by method of Baker and Frank. Practical Clinical Biochemistry: Page No. 902.

18. SK Jindal. COPD: The Unrecognized Epidemic SK Jindal. COPD: The Unrecognized Epidemicin India. (C) Supplement to Japi, 2012;60:14-16.

19. Laura Fregonese and Jan Stolk. Hereditary alpha- 1antitrypsin deficiency and its clinical consequences. Orphanet Journal of Rare Diseases. 2008;3:16.

20. Hedstrom AK, Hillert J, Olsson T, Alfredsson L. Smoking and multiple sclerosis susceptibility. Eur J Epidemiol. 2013;28:867-74.
21. Ramasamy R, Murugaiyan SB, Arulkumaran U, Sathiya R, Velu KV, Gopal N. Comparative study of adenosine deaminase activity, insulin resistance and lipoprotein (a) among smokers and healthy non-smokers. Int J Res Med Sci. 2016;4:1950-3.

22. Siddiqi SS, Ahmed J, Islam N, Ashraf SMK, Mishra SP. A study on the modulation of ADA activity in monocytes of type-2 diabetic patients by antioxidants. Journal of Indian academy of clinical medicine, 13(1):18-21.

23. Richard S. Bruno, Maret G. Traber; Cigarette Smoke Alters Human Vitamin E Requirements, The Journal of Nutrition, 2005;135(4):671-674.

24. Ismail NM, Harun A, Yusof AA, Zaiton Z, Marzuki A. Role of Vitamin E on Oxidative Stress in Smokers. The Malaysian Journal of Medical Sciences : MJMS. 2002;9(2):34-42.

How to cite this article: Raut A.M, Andure D.V, Padalkar R.K, Patil S.M, Bhagat S.S. A study of interaction of cigarette smoke with alpha-1 antitrypsin and adenosine deaminase in patients of chronic obstructive pulmonary diseases (COPD) and antioxidant role of vitamin E. Int J Clin Biochem Res. 2018;5(4):521-525. 